\title{
ELEMENTOS PLATÓNICOS Y ARISTOTÉLICOS Y ORIGINALIDAD TOMISTA EN LA CUARTA VIA O PRUEBA DE LA EXISTENCIA DE DIOS
}

1. Origen platónico de la cuarta vía tomista. La cuarta vía con que Santo Tomás prueba la existencia de Dios tiene su origen en Platón.

La visión genial del filósofo de la Academia, su contribución definitiva al acervo cultural de Occidente, es el descubrimiento de la participación: cualquier perfección en grado finito es recibida o participada de otra perfección en grado superior $y$, en definitiva, infinita. Vale decir, que lo menos no es sino por dependencia de lo más, lo limitado de lo ilimitado, lo contingente de lo necesario, lo múltiple de lo uno, etc. $\mathrm{Y}$ así un cuerpo bello -es el ejemplo de Platón en El Baquete_ supone, por encima de él un alma bella, por participación de la cual él es bello y la Idea o Realidad en sí, infinita, de Belleza, de la que reciben su belleza en mayor o menor grado - y en dependencia inmediata las inferiores de las superiores - todas las cosas bellas. Fundado en el hecho de la existencia de las realidades finitas del mundo y del hombre, por exigencias de la participación, Platón demuestra la existencia de las Ideas, de las realidades que son por sí mismas, imparticipadas y, por tal razón, infinitas; ya que sin el influjo o participación de éstas, aquéllas no tendrían razón de existir. Es la Dialéctica platónica, que asciende desde los grados inferiores de la materia al cielo empíreo del espiritu para alcanzar en la unidad infinita o pura de las Ideas o Esencias la razón suprema de ser de la realidad múltiple y finita de las cosas materiales. Estas son porque aún persiste en ellas el reflejo _-más o menos lejano, según se trate de realidades materiales o espirituales_- de las Ideas; pero no son las Ideas "por la materia loca" o caótica, la cual, al recibir como sujeto aquel influjo o participación de las Ideas, las diluye en la multiplicidad finita de su "no ser".

La participación platónica implica, pues: 1) la realidad de las Ideas o Esencias puras ejemplares en si, imparticipadas e infinitas; 2) el sujeto, que recibe y limita la perfección de estas Ideas, y 3) el influjo de éstas sobre el sujeto que determina la perfección de la múltiple y diversa realidad finita, que no es, por eso, sino por dependencia de aquéllas.

2. Perfecciones puras y perfecciones imperfectas. Platón no supo distinguir entre la participación real y la participación lógica: entre la participación del ser o de las perfecciones puras, también llamadas trascendentales, y la participación de las perfecciones esencialmente imperfectas, aprehendidas mediante conceptos predicamentales. 
Yorque dos son los tipos de perfecciones que se presentan a nuestra inteligencia: I) las que en su concepto no encierran imperfecciones, es decir, perfecciones que, aunque en su existencia sean finitas o imperfectas y, por eso mismo, contingentes, en su esencia o concepto no incluyen finitud o imperfección alguna ni por ende, contingencia. Las perfecciones puras o simplemente tales no son sino el ser y las notas que los escolásticos llamaban trascendentales, con él identificadas, tales como la unidad, la belleza, la verdad, la bondad y también la inteligencia y la voluntad o amor, identificadas, respectivamente, con las dos últimas perfecciones cuando ellas alcanzan el ápice del acto de ser. Semejantes perfecciones, que el entendimiento humano encuentra en torno suyo en estado de existencia imperfecta o finita y contingente, en su esencia no incluyen imperfección alguna y, por lo mismo, pueden existir en estado de pura perfección o de imparticipación e infinitud.

2) En cambio, las otras perfecciones no sólo en su existencia sino en su misma esencia incluyen imperfección, y son, por eso, esencialmente imperfectas y no pueden existir nunca en grado perfecto e imparticipado e infinito. Tales son las perfecciones que por su misma esencia implican potencia o imperfección, como las sustancias materiales y aun las espirituales cuya esencia no es su existencia, y todos los accidentes. En otros términos, son perfecciones esencialmente imperfectas todas las perfecciones predicamentales, todas las perfecciones que en su concepto implican una dualidad de esencia y existencia. Tales perfecciones, al no poderse identificar con la existencia o acto, implican una esencial limitación o potencia y, por ende, no pueden existir, en cuanto tales, en estado de pura perfección, en grado infinito o imparticipado. De aqui que no se pueda pasar de la existencia de tales perfecciones, esencialmente participadas, a la existencia de las mismas en estado puro. Para pasar de tales perfecciones a la perfección imparticipada e infinita de las mismas, es menester despojar a dicha perfección de toda imperfección, y consiguientemente, de las notas esenciales de aquellas perfecciones; con lo cual las mismas dejarían de existir con su formalidad propia. Por ejemplo, para que un cuerpo pudiese existir en un estado de perfección pura o infinita debería ser despojado de toda imperfección y, consiguientemente, de la nota de materia - esencialmente imperfecta - lo que equivale a decir que no podría existir formalmente como cuerpo. De lo cual se sigue que si el ser, ver. dad, bondad y belleza - y lo mismo inteligencin y voluntad o amor- pueden existir en estado puro o despojados de toda imperfección, no puede afirmarse otro tanto del cuerpo, de la cantidad, del color o de la ubicación o de ninguna perfección predicamental o esencialmente imperfecta. Si la verdad limitada implica la Verdad en si, el cuerpo limitado no implica ni puede implicar un Cuerpo en si, infinito, pues tal cuerpo infinito es contradictorio, ya que el cuerpo implica esencialmente materia y ésta a su vez potencia o limitación. Lo que la existencia de un cuerpo implica es la perfección del cuerpo en 
grado infinito: la perfección del cuerpo no formal sino eminente: el Acto puro que incluye en su perfección infinita la perfección del cuerpo sin su esencial imperfección de cuerpo. En otros términos, también la perfección real, finita del cuerpo -lo mismo habría que decir de cualquier perfección esencialmente imperfecta_ implica la perfección imparticipada y, como tal, infinita; sólo que, al alcanzar tal estado de absoluta Perfección, deja de ser cuerpo -o tal determinada perfección imperfecta_ bien que en su infinitud encierra toda perfección, también toda la perfección de cuerpo, pero no de un modo formal o como cuerpo, sino eminente o superior.

$\mathrm{La}$ existencia de los seres finitos, que son verdaderos, buenos, bellos y unos, implica, pues, la existencia del Ser o Acto o Existencia de la Verdad, Bondad, Belleza y Unidad en sí y de las consiguientes Inteligencia y Voluntad o Amor en sí.

En cambio, la existencia del cuerpo o de un objeto blanco no implica el cuerpo o la blancura en sí, que no pueden existir formalmente tales, sino de la Perfección o Acto Puro, infinito y libre de las limitaciones esenciales del cuerpo y de lo blanco, por participación del cual es el cuerpo y lo blanco esencialmente finitos en toda gama de sus múltiples realizaciones.

Lo que sucede es que frente a estas perfecciones esencialmente imperfectas, precisamente porque son finitas, la inteligencia humana es capaz de abstraer su esencia en sus notas genéricas sin sus notas específicas, o sus notas específicas sin sus notas individuantes, es decir, es capaz de formar conceptos universales univocos; los cuales en sus notas más abstractas constituyen los diez predicamentos o géneros supremos.

3. Expresión conceptual univoca de la participación lógica y expresión conceptual análoga de la participación real. Ahora bien, tales nociones son perfectamente univocas, vale decir, alcanzan perfecta unidad conceptual en la noción genérica o específica, prescindiendo de las notas inferiores -específicas o individuantes respectivamente-, con las cuales, sin embargo, están identificadas en el orden real. Tales nociones, por eso, son abstractas y su unidad es puramente conceptual y no real. En la realidad sólo hay hombres y objetos blancos individuales y no el hombre o lo blanco en sí y menos aún la humanidad o la blancura.

Identificados con los individuos existentes -en acto o en potencia o posibilidad- en cuanto a lo que ellas expresan - no en cuanto al modo abstracto como lo expresan, y que no es atendido en la predicación o atribución en el juicio a los individuos reales - tales nociones que en su existencia conceptual realizan la esencia genérica o especifica en todo su ámbito -precisamente gracias a la abstracción o prescindencia de las notas inferiores con que existen en la realidad - se conciben como la realidad pura de la que participan y por la que son los seres individuales. Así Juan o este hombre blanco 
se conciben tales por participación de la esencia de hombre o de lo blanco, a saber, de las notas reales de hombre y de blanco, que sin embargo como tales - como hombre o blanco no individual_ únicamente existen por abstracción en la inteligencia.

Semejante participación no es real, pues no hay ni puede haber un hombre en sí o un blanco en sí, ya que sólo puede existir este o aquel hombre u objeto blanco individual, puesto que en el plano de la existencia la realidad es esencialmente individual: una esencia abstracta universal existente sería una y mútiple a la vez y bajo el mismo aspecto real, lo cual es contradictorio.

La pertenencia o identidad de la esencia con los individuos atribuida en el juicio mediante la cópula verbal es real precisamente porque los individuos están identificados con ella, pero la atribución de tal esencia al individuo, la participación de éste respecto a tal esencia en sí, abstracta, es exclusivamente lógica o conceptual, precisamente porque el término imparticipado, del que participa el individuo real, no existe ni puede existir formalmente tal, sino únicamente en el concepto de la mente.

Tales esencias pueden ser atribuidas en el juicio con perfecta identidad como predicados del sujeto real individual, porque son nociones esencialmente finitas o imperfectas, capaces de ser aprehendidas por la mente humana como tales en conceptos unitocos, a saber, con prescindencia perfecta de las notas inferiores, especificas o individuantes, con las que se encuentran identificadas en el orden real.

En cambio, la inteligencia humana no puede prescindir perfectamente de las diversas y múltiples realizaciones del ser - y de las notas trascenden. tales con él identificadas: unidad, verdad, bondad, etc.- precisamente porque el ser es realmente infinito, desde que en él están incluidos los infinitos entes posibles y existentes y el Ser o Acto puro de Dios y, consiguientemente, sólo puede ser aprehendido en una noción imperfectamente una o análoga. Vale decir, que cuando se trata del ser o de las perfecciones puras, con él identificadas, y de su participación real, la inteligencia humana sólo puede expresarlas imperfectamente mediante conceptos relativa o analógicamente idénticos.

La atribución unívoca de las perfecciones imperfectas tiene su fundamento en su limitación; la cual las hace aprehensibles por conceptos abstractos finitos y expresables en una participación puramente lógica, pese a la identidad real de las notas expresadas en tales conceptos con la realidad individual.

Esta distinción precisa de las perfecciones puras y de las perfecciones esencialmente imperfectas, con la consiguiente distinción entre la participación real y la participación lógica, con que se expresan, respectivamente en los conceptos univocos o predicamentales y en los análogos y trascendentales, 
estaba reservada a Santo Tomás de Aquino, quien habia de alcanzarla mediante una profundización del concepto mismo de ser.

4. Los dos errores de Platón en la noción de participación.

A) Platón no alcanzó a ver que si las perfecciones reales, como el ser, lo bueno y lo verdadero - las perfecciones puras o trascendentales- existentes en grado limitado implican la Perfección o el Ser, la Verdad y la Bondad en grado infinito o imparticipado, no sucede lo mismo con las perfecciones esencialmente imperfectas — con las perfecciones mixtas o predicamentales- ya que las mismas no pueden existir en grado de perfección pura o infinita sin perder su formalidad, es decir, sin dejar de ser tales perfecciones. La existencia de tales perfecciones esencialmente imperfectas $y$, como tales, participadas, no implica, pues, una perfección imparticipada del mismo género o especie, sino una Perfección pura, que incluye en grado infinito toda la perfección de la perfección imperfecta sin su esencial imperfección formal genérica o específica o, lo que es equivalente, que la incluye de un modo eminente.

Extasiado ante el descubrimiento de la participación y como enceguecido por ella, Platón no acierta a distinguir, pues, ambas participaciones: real o de las perfecciones puras y lógica o de las perfecciones esencialmente imperfectas, las confunde y hace a ambas reales de tal modo que no sólo la existencia de un objeto bueno implica la bondad en sí sino que un hombre y un objeto blanco implican el hombre y la blancura en sí.

Estas perfecciones imparticipadas o en estado de puras esencias son las Ideas. Al confundir la participación real con la lógica, Platón identificó el orden lógico con el ontológico y llevó, consiguientemente, al plano de la realidad el orden conceptual, con todas sus leyes: hizo de la Lógica o Dialéctica una Metafisica. Así como más tarde, repitiendo la identificación de ambos planos, lógico y real, pero con un acento inverso, absorbiendo no el concepto en el ser como Platón, sino el ser en el concepto o Idea, Hegel identificaría la Metafísica con la Lógica.

$B$ ) Intimamente unido al anterior, Platón cometió un segundo error: condujo la multiplicidad y diversidad específica y genérica al plano imparticipado o infinito: a la constelación de Ideas o Perfecciones imparticipadas, a que llevan las múltiples y diversas realidades finitas existentes, y entre las cuales se establece una serie de relaciones complicadísimas — más aún, imposibles y absurdas en un plano real y sólo posibles en dos planos esencialmente distintos: lógico y real_ de inclusión y exclusión, como son las relaciones conceptuales de género y especie, de lo mismo y lo otro, etc.

A tal conclusión llega lógicamente Platón, porque las perfecciones esencialmente imperfectas, aun llevadas a un estado de imparticipación -que sólo puede ser conceptual o lógico y nunca real, como él pretende — no pue. 
den identificarse, pues incluyen perfecciones excluyentes y. hasta opuestas a otras: los diferentes géneros y especies.

Pero si corregimos el primer error de Platón y tomamos conciencia de que toda perfección finita implica una perfección imparticipada y en tal estado toda perfección debe ser y existir por sí $-a$ se- $-\mathrm{y}$, consiguientemente, infinita, comprenderemos que en este plano no hay perfección imperfecta y que todas las perfecciones son puras o trascendentales, en el sentido clásico de este término y no en el kantiano posterior.

Ahora bien, las perfecciones puras, como la unidad, la verdad, la bondad y la belleza, con la inteligencia y la voluntas o amor, identificadas con la Verdad y la Bondad en el ápice de su Acto puro de Ser, lejos de excluirse, se identifican y no son sino el mismo ser, en cuanto es considerado por nuestra inteligencia con relación a la indivisión, al entendimiento o a la voluntad. En otros términos, las perfecciones puras no son sino propiedades trascendentales del ser, realmente identificadas con éste y sólo conceptualmente distintas por una relación de nuestra inteligencia. La existencia de seres múltiples y diversos, implica, pues, la existencia de perfecciones en estado imparticipado y, por ende, de perfecciones que son por sí mismas, y por eso mismo, sin limitación alguna, infinitas y, consiguientemente, sin la imperfección de las perfecciones esencialmente imperfectas. Ahora bien, tales perfecciones puras, imparticipadas e infinitas, están identificadas, según acabamos de ver, y no son sino el Ser o Existencia en sí, que, en la infinitud de su Acto o Pefección pura y simple, identifica consigo todas las perfecciones puras: Unidad, Verdad, Bondad, Belleza y las consiguientes de Inteligencia, Voluntad y Amor.

Si lo purificamos de los dos errores mencionados: 1) el de hacer real la participación lógica, y 2) el de fundamentar la realidad participada en múltiples realidades imparticipadas o Ideas, la Dialéctica platónica conduce desde la realidad finita, múltiple y diversa del mundo y del hombre a una realidad única imparticipada, que no es sino el Ser o Existencia en sí y por sí: el Acto o Perfección pura infinita de Dios.

5. Necesidad de la distinción de causa ejemplar, formal y eficiente introducida por Aristóteles. Mas para que el genial descubrimiento platónico de la participación lograse todo su verdadero y preciso alcance, era menester la distinción clara de las causas ejemplar, formal y eficiente, confundidas en él.

El jefe de la Academia conoció y subrayó la causa ejemplar o formal extrínseca, pero no supo distinguirla de la formal intrínseca precisamente porque desconoció la causa eficiente.

En efecto, del hecho de la existencia de perfecciones limitadas Platón concluyó la existencia de una misma perfección en grado ilimitado, por participación de la cual son aquéllas en determinada medida. Las cosas munda- 
nas son tales por participación de las Ideas. Éstas son los modelos o ejemplares que se proyectan y dan esencialidad a los objetos materiales, sin perder ni contaminarse en lo más mínimo en su esencial pureza en este contacto con la materia.

Ahora bien, el problema es saber, en primer lugar, en qué consiste esta participación o, en otros términos, qué es lo que las Ideas comunican a la materia - sujeto informe- y, en segundo lugar, cómo se realiza o se lleva a cabo tal comunicación.

Con mitos e imágenes —que si bien sugieren, a la vez complican el tema_Platón se ha referido siempre a la acción ejemplar de las Ideas - principalmente en el Timeo - al destello que ellas proyectan o influjo que introducen en la materia, sin precisar nunca si tal destello o influjo es algo distinto y separado de las Ideas e introducido como constitutivo intrínseco en la realidad material, producido en las cosas como su determinación formal o esencial, o si son las mismas Ideas o algo inseparado de ellas que penetra y transforma la materia, pero sin llegar a constituir por su propia esencia los objetos mundanos. En otros términos, toda esta ambigüedad en que queda el pensamiento platónico en tema tan fundamental proviene de no haber distinguido entre causa ejemplar o formal extrinseca de las Ideas y el efecto por ellas producido en las cosas como un acto determinante o causa formal intrinseca, introducido en la materia para constituirla en tal determinada esencia.

Y no pudo distinguir entre ambas, porque no conoció la causa eficiente: el principio extrínseco que con su influjo determina y da existencia a otro ser fuera de sí en una determinada esencia, el cual, por eso, no es sino por dependencia de aquél.

La causa ejemplar puede explicar la constitución de las notas esenciales de un ser: es el caso de la Inteligencia divina que constituye las esencias de la mente del artista que elabora el ejemplar bello. Pero por sí sola es ineficaz para dar existencia a una determinada esencia fuera de su inmanencia intelectiva. Para que tal esencia así gestada y existente en un acto extrinseco a ella misma, como es el acto de la inteligencia que la constituye, llegue a poseer su acto intrinseco con independencia de la inteligencia que la constituye, es menester la causa eficiente, que con su influjo confiera existencia a su acto esencial o forma intrinseca.

Vale decir, que en Platón estaban confusas las causas ejemplar y eficiente, porque no se distinguían con precisión en el efecto su constitución formal y su realización en si, su esencia y su existencia; confusión que a su vez tenf́a su raíz en la confusión de las participaciones real y lógica. ${ }^{1}$

1 Tal confusión tendría su raíz en la supremacia que Platón otorga a la esencia sobre la existencia. Tal es, al menos, la tesis que, con argumentos convincentes, sustenta $\mathbf{E}$. Gilson en su magnífica obra, El ser y la esencia, págs. 26-44 (traducción de L. de Sesma, Desclée, 
A Aristóteles debe la Filosofía el hallazgo de esta distinción con el descubrimiento de la causa formal y de su causa correlativa extrínseca, que es la causa eficiente; la cual determina a aquella como al acto constitutivo de la esencia, dentro del ordenamiento de las cuatro causas: de la materia y forma, que constituyen intrínsecamente los seres materiales y de las causas eficiente y final, que con su influjo eficaz las determina extrínsecamente a su existencia.

Entre la Idea ejemplar platónica y la realidad por ella participada, como su efecto, Aristóteles introduce la Causa eficiente, que con su influjo determina o produce la forma o acto esencial de la materia y da realidad en sí a los objetos mundanos de acuerdo a las exigencias de aquella causa ejemplar. La forma intrínseca de Aristóteles es la idea platónica introducida en la esencia misma del ser material para constituirlo en tal determinada especie como su acto determinante, producido por la causa eficiente de acuerdo a las exigencias de la Idea o Causa ejemplar existente en la inteligencia, ya de la propia causa eficiente -Dios o el hombre - ya de la Causa eficiente primera - Dios- para las causas eficientes carentes de intelecto.

Con la distinción de ambas causas Aristóteles da explicación a la participación o realidad producida por el acto o forma intrinseca mediante una causa eficiente. La doctrina de la participación platónica es incorporada y superada en la doctrina de las causas de Aristóteles y, en definitiva, en su doctrina del acto y la potencia. En efecto, la participación se realiza mediante la actuación de una materia y, en general, de una potencia, por la forma o acto realizado por el influjo de otro ser, que ya posee esa perfección o acto - -en su formalidad específica o de una manera eminente- y que es la causa eficiente.

Sin embargo, en su afán de poner en relieve la causa formal y eficiente, Aristóteles descuidó y dejó casi de lado la causa ejemplar, tan fundamental para la explicación de la participación o comunicación real del ser, y perdió, o diluyó al menos, por eso, el sentido más hondo de la participación de la existencia - que estaba reservada a Santo Tomás- para quedarse casi exclusivamente en la de la forma o acto esencial.

6. La participación, esclarecida con la doctrina de las causas de Aristóteles, sólo adquiere todo su auténtico sentido en Santo Tomás mediante la profundización de la doctrina del acto y la potencia con el descubrimiento de la distinción real de esencia y existencia en la creatura. Al genio metafísico de

De Brouwer, Buenos Aires, 1951). Para Platón las Ideas, la realidad imparticipada y fuente de toda la realidad mundana existente, propiamente no son existencias, sino puras esencias. La existencia sería la realidad degenerada del mundo material, que es por participación de la Esencia o realidad pura de las Ideas.

En contra de esta tesis de Gilson está R. Loriaux, "L'Etre et l'Idée selon Platon", en Revue Philosophique de Louvain, págs. 5-55, febrero de 1952. 
Santo Tomás estaba reservada la integración de lo mejor del pensamiento platónico y del pensamiento aristotélico: de la participación y de la causa ejemplar de las Ideas, de aquél, y de las causas formal y eficiente, de éste, en una síntesis superior estructurada en la doctrina aristotélica del acto y la potencia, ahondada hasta sus raíces más profundas y ampliamente desplegada en todo su alcance mediante la distinción real de esencia y existencia en el ser finito, con la consiguiente distinción precisa de las dos participaciones: de la lógica o de las perfecciones esencialmente imperfectas o predicamentales de géneros o especies y de la real o de las perfecciones puras o trascendentales, que responden, respectivamente, a la esencia y a la existencia. Vale decir, que la concepción aristotélica del acto y la potencia, profundizada por Santo Tomás hasta su más honda realización: la esencia y la existencia, venía a purificar, fundamentar y dar la fórmula cabal al gran descubrimiento platónico de la participación.

El Angélico Doctor distingue por vez primera y aprehende el sentido y alcance de las dos participaciones a que antes hemos aludido (n. 2): una lógica o de las esencias específicas y genéricas, de las perfecciones esencialmente imperfectas o predicamentales, y otra real de la existencia concreta de los seres o de las perfecciones o propiedades trascendentales.

La existencia de esencias participadas implica un Ser o Existencia imparticipada e infinita, como su Causa eficiente y ejemplar; ya que la existencia de aquella esencia finita implica la existencia de esa esencia en grado infinito, la cual ya no es tal esencia formal sino la pura Existencia que de una manera eminente la contiene.

Pero aun las esencias consideradas en sí mismas o en su constitución. intrínseca, con independencia de su actual existencia, implican también y siempre la Existencia imparticipada, no como Causa eficiente -pues tales esencias no existen, no son reales en su propio o intrínseco acto- sino como Causa puramente ejemplar.

Esclarecido el alcance y modo de realización de la participación platónica con la distinción aristotélica de las causas formal y eficiente, e integrada por Santo Tomás dentro de la doctrina del acto y la potencia, descubierta por el propio Aristóteles, pero que sólo en el Aquinate logra todo su alcance gracias a la distinción de esencia y existencia en el ser finito con la consiguiente distinción precisa de las dos participaciones, real y lógica, con lo cual el descubrimiento platónico obtenía todo su valor: Santo Tomás ha alcanzado en toda su pureza y significación la doctrina de la participación real y ha logrado aprehender y formular en toda su fuerza, mediante ella, la cuarta vía o argumento de la existencia de Dios, fundado en la participación real tanto de la existencia como de la esencia del ser finito. La gran verdad platónica de la participación, que fue esclarecida con la distinción causal, pero a la vez disminuida y casi destruida en su misma esencia con el menospre- 
cio y olvido de la causa ejemplar y por la ignorancia de la distinción real de esencia y existencia por el Estagirita, sólo.en Santo Tomás es purificada totalmente de sus errores y esclarecida en todo su verdadero alcance y fundamentación dentro de una estructura aristotélica del acto y la potencia, pero sólo alcanzada hasta en sus últimas raíces con la distinción real de esencia y existencia como constitutivo del ser finito —creatura_- frente a la pura Existencia imparticipada como esencia de Dios. Con ella reencontraba en toda su pureza lo auténtico del pensamiento platónico con la distinción de las dos participaciones: la real y contingente de la existencia, y la necesaria de las esencias de los seres finitos.

Con la noción de la participación ontológica de Platón y la del acto y la potencia de Aristóteles con la distinción de esencia y existencia en toda creatura -mediante la noción de creación: productio rei ex nihilo sui et subjecti, desconocida por los filósofos paganos, y de la existencia de las formas puras de los ángeles de la Revelación cristiana- Santo Tomás logra aprehender, pues, en toda su fuerza la doctrina de la participación, con la de-velación - probablemente el único en toda la historia de la filosofía_2 de la estructura íntima del ser, que se realiza como Acto o Existencia pura en su Causa imparticipada eficiente, de la cual descienden por creación, compuestos de esencia y existencia, los seres finitos: de esencia por participación necesaria dependiente de la Inteligencia divina, y de existencia por participación libre dependiendo de la Voluntad divina.

Insistiendo en este pensamiento fundamental que nos pone en contacto con el genio de Santo Tomás, en última instancia el Aquinate ha podido alcanzar en su pura esencia la realidad de la participación, vislumbrada por Platón, porque ha logrado aprehender en toda su complejidad y desde su raíz o Causa primera el ser y sus constitutivos de esencia y existencia en sus diversas y múltiples realizaciones, sólo imperfectamente unificadas, por eso mismo, en un concepto análogo de las mismas, vale decir, porque ha logrado aprehender hasta su raíz primera la doctrina aristotélica del acto y la potencia. Participación y analogía son dos nociones correlativas, que abarca la realidad del ser desde su fuente imparticipada hasta sus mínimas realizaciones finitas, la primera, y que la expresa conceptual o lógicamente en toda su diversidad y multiplicidad, la segunda. Si Platón y Aristóteles no pudieron alcanzar la noción de participación en toda su fuerza, es porque no lograron aprehender en toda su complejidad la noción de ser, que sólo alcanza a hacerlo en su visión metafísica genial Santo Tomás, lograda con la captación de los apor-

2 E. Gilson, El ser y la esencia, págs. 74 sigs., traducción castellana de L. de Sesma, Desclée De Brouwer, Buenos Aires, 1951; y C. Fabro, "Dall'Essere de Aristotele allo 'Esse' de Tommaso", en Mélanges E. Gilson, págs. 227 sigs., Vrin, 1959. . Ver también y sobre todo C. Fabro, Partecipazione e Casualitá secondo S. Tommaso d'Aquino, Societá Editrice Internazionale, Torino, 1960 . La obra ha sido editada simultáneamente en francés por el Institut Superieur de Philosophie de Louvain, 1960. 
tes de los dos mencionados filósofos, purificados y ahondados hasta sus últimos fundamentos. Noción ésta del ser, tan difícilmente lograda en su ápice por Santo Tomás, que luego se pierde, incluso en no pocos escolásticos y tomistas, porque se pierde esa cabal y difícil comprehensión conceptual analógica del ser. ${ }^{3}$

7. Formulación de la cuarta via o demostración tomista de la existencia de Dios por la participación del ser. He aquí la primera forma de la cuarta vía de Santo Tomás, tal comó ordinariamente se la suele formular, sobre la base del hecho de la existencia de perfecciones en diverso grado, con un movimiento dialéctico de evidente inspiración platónica, que evoca el argumento del mismo para probar la existencia de las Ideas, pero enriquecido con los elementos aristotélicos y tomistas ya mencionados.

$A$. El punto de partida no es otro que la existencia, en diversa medida finita, de las perfecciones puras o reales, que por su misma finitud no pueden ser la Perfección - de sí ilimitada_y deben ser, por ende, participadas, haber recibido su perfección de la Perfección en sí. El término o conclusión final de este argumento no puede ser sino la existencia de un Ser o Perfección pura imparticipada y, por eso, infinita y, por la misma razón, identificando consigo todas las perfecciones puras en una sola Realidad o Existencia: en Dios.

Como todos los argumentos tomistas de la existencia de Dios, también éste se funda en el hecho de la existencia de algo, que no existiría si no existiese la Existencia en si o Dios.

He aquí el argumento: en el mundo se dan o existen el ser y las per. fecciones puras, con él identificadas, de unidad, bondad, verdad y belleza, en diversos grados, siempre finitos. Ahora bien, semejante ser y perfecciones puras en grado finito no son el ser o perfección, sino que participan del mismo. Porque el ser o perfección pura no encierra en su esencia imperfección o limitación alguna. Por consiguiente, si existen en grado limitado, es porque no son el ser o perfección pura, sino que la han recibido o participado inmediata o mediatamente de él, en un grado finito. De otra suerte, de no ser participados sino el ser o perfección misma, lo serían de un modo infinito y serían el Acto o Existencia pura. Toda perfección o ser en grado finito es, por consiguiente, una perfección participada y remite siempre a otra perfección de la que recibe o participa su perfección. Y como se trata de una perfección que no es sino que ha llegado a tener perfección, ha debido recibirla como una forma o determinación intrínseca causada en ella no sólo de un modo ejemplar, sino también eficiente. De otro modo no habría llegado a existir en un ser que no era ni tenía tal perfección.

3 C. Fabro, "L'Obscurcissement de 1"Esse' dans l'école thomiste", en Revue Thomiste, págs. 443 sigs. París, $195^{8}$. 
Ahora bien, la perfección causante de la perfección limitada o es la Perfección misma en sí e imparticipada, o es a su vez una perfección participada. En esta segunda hipótesis, tal perfección debe ser participada o cau. sada ejemplar y eficientemente por otra y así sucesivamente hasta llegar a la Perfección imparticipada y existente por sí misma. Porque no se puede admitir una serie infinita de perfecciones participadas, encadenadas entre sí como causa y efecto, sin la Perfección primera imparticipada o incausada, en este proceso causal. En efecto, el argumento parte de un hecho accesible a nuestra inteligencia por nuestra experiencia: la existencia de perfcciones causadas en grado finito. Ahora bien, si la serie de perfecciones causadas fuese infinita, no habría Perfección primera imparticipada y, en tal hipótesis, ningún ser habría recibido esa perfección y toda la serie de perfecciones participadas finitas no habría llegado a participar su perfección, no habría llegado a existir y tampoco existiría, por eso mismo, la perfección participada de cuya existencia parte y en la que se funda el argumento. Pero es un hecho que esta perfección existe, luego existe también la Perfección imparticipada primera, sin la cual aquélla no existiría.

Tal Perfección imparticipada es, por su concepto mismo, la Perfección en si, infinita, que se identifica con la Existencia - sin la cual no hay Perfección infinita - y con todas las demás perfecciones puras, a su vez identificadas con la Existencia. Pero tal Perfección o Existencia a se es precisamente lo que llamamos Dios. Luego Dios existe.

$B$. El mismo argumento podría partir del hecho de la existencia de las perfecciones esencialmente imperfectas o predicamentales. Tales perfecciones no son evidentemente la Perfección o Ser en si, pues son esencialmente imperfectas y, consiguientemente, finitas y suponen, en última instancia, la perfección imparticipada primera, de la que proviene causalmente aquella perfección. La diferencia con la formulación anterior del argumento reside en que, al llegar a la cima de la Perfección imparticipada, tal perfección deja de ser tal perfección determinada o predicamental —como creía Platón- y no es sino la Existencia o Perfección pura en sí e infinita, identificada con la Omniperfección, también con aquella perfección predicamental o determinada de la que parte el argumento, pero sin su esencial imperfección, vale decir, identificada con ella sólo de un modo eminente o en grado de absoluta infinitud.

8. Nueva formulación de la cuarta via o demostración de la existencia de Dios por la participación necesaria de la esencia de los seres finitos. A. El argumento puede tomar también como punto de partida el hecho -esta vez no contingente sino necesario- de las esencias, que se constituyen como posibles o capaces de existir, prescindiendo de su existencia actual y hayan de existir o no. En efecto, tales esencias se imponen de una manera necesaria y 
determinante a nuestra inteligencia como objetos trascendentes a ella. La mente humana ve que dos y dos son cuatro o que una montaña de oro es posible, es decir, que las notas de montaña y oro no se oponen, que no puede pensarse que no puedan existir solas o unidas, aunque no existan y no haya tal vez causa segunda de darles existencia; así como, por el contrario, se presenta a nuestra inteligencia como imposible o incapaz de existir una materia espiritual o un círculo cuadrado y, por más que ella se empeñe, no podría aprehenderlos como posibles.

Ahora bien, ¿por qué unas esencias u objetos se presentan como posibles o capaces de existir y otras como imposibles o incapaces de existir? ¿Qué es lo que las constituye tales? Hay una solución inmediata: la compatibilidad o no oposición de sus notas esenciales o la incompatibilidad opuesta.

Pero si ahondamos más, encontraremos que una esencia es un modo de existir, una determinada manera capaz de recibir o participar de la existencia. Todas las esencias o posibles suponen, pues, la Existencia, de la que son un modo determinado o finito de participarla. Si por absurdo no hubiese o no existiese la Existencia, nada sería posible y no se constituirían ni serían las esencias. Por el mismo motivo, tampoco nada sería imposible, ya que lo imposible y lo absurdo es la incompatibilidad de tal conjunto de notas para participar de la Existencia. Si, pues, no fuese o existiese la Perfección o Existencia pura - ni valdría acudir a la instancia inmediata de existencias participadas, ya que suponen y existen, en definitiva, por la Existencia imparticipada - no habria esencias, se destruiría el mundo de los posibles; el cual se presenta como necesario y trascendente e independiente de la actividad de nuestra inteligencia, la cual no puede pensar tales esencias o posibles, no por una imposibilidad subjetiva, sino objetiva; la necesidad con que se imponen a nuestra mente, no proviene, por ende, de ésta, sino por su participabilidad de la Existencia absoluta y trascendente.

Este mundo inmutable de las esencias y de sus relaciones -objeto de la Metafísica y también de las Matemáticas- y que se impone a nuestro entendimiento de un modo necesario y absoluto, se apoya e implica la existencia de la Perfección o Existencia imparticipada, sin la cual nada sería posible ni imposible, objeto pensable ni impensable o absurdo.

$B$. Lo dicho de la doble categoría de las perfecciones existentes vale también para las puras esencias o posibles. Las esencias puras suponen formalmente la misma Perfección -identificada con la Existencia- pura e infinita; las esencias imperfectas implican también la Existencia pura, que las fundamenta de una manera eminente, o sea; en cuanto en su Perfección infinita incluye toda la perfección de las esencias imperfectas sin su esencial y específica imperfección.

Esta Existencia pura e infinita, por el mero hecho de encerrar toda perfección, fundamenta toda participabilidad o modo finito posible de existir 
fuera de ella, es decir, fundamenta todas las esencias posibles. Por el mero hecho de ser o existir la Perfección o Existencia infinita, ya están fundamentadas todas las esencias finitas posibles.

Y como quiera que tal perfección o Existencia pura es, por su concepto mismo, infinita, es también Acto puro de Entender: Intelección pura e infinita de si, Comprehensión exhaustiva de su propia Perfección.

De aquí que si la Existencia o Esencia pura de Dios fundamenta de un modo necesario las infinitas esencias finitas, su Intelección -realmente identificada con su Existencia o Esencia - las constituye formalmente también de un modo necesario: al comprehender exhaustiva y necesariamente su infinito Acto de Existir, su divina Esencia, la Inteligencia de Dios ve en Ella los infinitos modos finitos de participabilidad de la misma, constituye las infinitas esencias finitas, de un modo tan necesario y absoluto como es la Visión de su propia Esencia, lógicamente anterior e independiente de su Voluntad, que supone esas esencias constituidas y elige libremente de entre ellas a las que quiere otorgar existencia.

La Inteligencia divina, de un modo necesario y absoluto constituye, pues, el mundo de las esencias, las ve y da consistencia en la comprehensión de su divina Esencia o Existencia -que en Dios son real y formalmente idénticascomo participabilidades de su Existencia, como modos capaces de recibir o participar de su Existencia, las ve en Ésta, pero como capaces de existir fuera de Ella, ya que la finitud esencial no cabe en la Perfección o Acto puro e infinito de Dios.

En síntesis, las esencias finitas, como estructuras objetivas que se imponen a la mente humana, suponen a su vez la Existencia pura de Dios, como su fundamento último, y la Inteligencia divina como la Causa ejemplar -no eficiente, pues estas esencias sólo son pero no existen en sí mismas- que las constituye formalmente y les da existencia extrínseca, como objetos, en el Acto de su Pensamiento.

9. Sintesis de la cuarta vía o argumento de la existencia de Dios por la participación. Las cosas existentes aparecen tales por participación contingente de la divina Existencia o Voluntad libre - realmente identificadas- y las esencias finitas por participación necesaria de la divina Existencia o Inteligencia, también realmente identificadas entre si.

Todo el ámbito del ser, en su esencia y existencia, desciende por participación necesaria y por participación libre o contingente de la Existencia pura de Dios: de su divina Inteligencia, como Causa ejemplar, necesariamente actuante, las esencias; y de su divina Voluntad, como Causa eficiente, libremente actuante, la existencia de aquellas esencias.

Esta cuarta vía o argumento de la existencia de Dios, originariamente vislumbrada por Platón en la prueba de las Ideas, y estructurada en toda su 
fuerza por Santo Tomás, conduce todo el ámbito del ser, en su esencia y existencia, hasta la Existencia pura e imparticipada, como hasta su origen y ápice trascendente primero y supremo, del que desciende por dos caminos: uno por vía de Causa ejemplar de la Inteligencia divina. necesariamente actuante: las esencias, tan necesarias y absolutas, por eso, como la misma Esencia o Inteligencia divina; y otro, por vía de Causa eficiente, de la Voluntad libre de Dios: los entes existentes, contingentes, por eso, en su existencia como la Causa libre que los determina al acto de existir.

Octavio Nicolás Derisi 